\title{
Response of bottom sediment stability after carp removal in a small lake
}

\author{
Ying-Tien $\operatorname{Lin}^{1 *}$ and Chin $\mathrm{H} . \mathrm{Wu}^{2}$ \\ 1 Disaster Prevention and Water Environment Research Center, National Chiao Tung University, Hsinchu 300, Taiwan \\ 2 Department of Civil and Environmental Engineering, University of Wisconsin-Madison, Madison, Wisconsin 53706, USA
}

Received 15 January 2013; Accepted 28 May 2013

\begin{abstract}
This study combined several features of acoustic and electromagnetic (EM) waves-based devices including sub-bottom profiler (SBP), side-scan sonar (SSS) and ground penetrating radar (GPR), and in situ sediment data to study responses of bottom sediments after carp removal in Lake Wingra. In 2007, i.e., before carp removal, macrophytes only grew to a water depth of $2 \mathrm{~m}$. Meanwhile, GPR data showed no visible sublayer in vegetated regions, while SBP data revealed a loose and fluffy sediment layer in unvegetated regions, easily affected by wave or current motions. The field data showed that suspended sediment concentrations (SSC) were much greater in unvegetated regions than those in vegetated regions during a one-day wind event, and the resuspended sediments could remain suspended in the water column for two days. In 2009, i.e., after more than half $(51 \%)$ of carp were removed, the fluffy sediment layer recognized by SBP became thinner or even disappeared, and both SBP and SSS results showed that submerged macrophytes started growing in deeper water. In situ sediment data presented that bulk sediment density and critical shear stress became greater, and bottom sediments consolidated and were harder to be resuspended. Secchi depth collected between 2008 and 2010 was greater than that in the previous 10 years, indicated clearer water state. In short, the fluffy sediment layer because of carp activities may be the main source for suspended sediments to deteriorate water quality. Removal of carp is crucial for stabilizing bottom sediment and improving water clarity in this small lake.
\end{abstract}

Key words: Acoustic and electromagnetic signals / carp / sediment sublayer / sediment stability / suspended sediment concentration

\section{Introduction}

In aquatic environment, carp, an exotic benthivorous fish, have negative effect on growth of macrophytes (Roberts et al., 1995) and the stability of bottom sediments (Breukelaar et al., 1994). Carp can physically disturb and resuspend bottom sediments through feeding behavior (King and Hunt, 1967). Subsequently, resuspended sediments can thereby diminish light availability, which induces significant decrease of aquatic macrophytes in the water body (Hamilton and Mitchell, 1997; Miller and Crowl, 2006). Lougheed et al. (1988) showed that water turbidity and nutrient loading increased proportionally with the biomass of spawning carp in experimental enclosures. Carp are also known to consume Chara aspera that stabilize bottom sediments, or directly damage macrophytes during foraging and spawning activities (Crivelli, 1983; Miller and Crowl, 2006). Decreased

\footnotetext{
*Corresponding author: kevinlin@ntu.edu. tw
}

macrophytes somehow weaken the capability to block waves and currents, which in turn enhance the potential for sediment resuspension (Losee and Wetzel, 1993; Jeppesen et al., 1998). In addition to bioturbation, carp excretion also can influence nutrient dynamics and biota composition (Matsuzaki et al., 2007). Furthermore, nutrients released from the bottom sediments are freely available to enhance algae blooms (Havens, 1991; Breukelaar et al., 1994). The two issues, sediment resuspension and algae blooms, can play an important role in determining water quality in lakes. Recent studies showed that two alternative states exist in shallow lakes: one with clear water, characterized with abundant macrophytes, and the other with turbid water, dominated by algae blooms (Jeppesen et al., 1990; Scheffer et al., 1997). The existence of carp elevates sediment resuspension, which is believed to be the main cause for turbid water in lakes (Scheffer et al., 1993). Zambrano et al. (2001) suggested a threshold of carp density causing a eutrophic state in lakes. To reverse a turbid lake to a clear-water and 
macrophyte-abundant lake, removal of carp from lakes can be a feasible biomanipulation approach (Cahoon, 1953; Schrage and Downing, 2004). Removal of carp directly eliminates potential of bottom sediment disturbances, which can increase bottom sediment stability.

After bottom sediments become more stable, chances of sediment resuspension induced by wave or current motions are reduced. Consequently, improved light availability in the water column can promote vegetation growth in deeper water (Madsen et al., 2001). Vegetation growth inherently provides drag forces in the water column, which extract momentum from flowing water and reduce wave energy and current velocities (Madsen and Warnke, 1983; Koch, 2001). The attenuated wave and current motions can therefore increase sedimentation, higher retention time for sediments and water and reduce the potential for sediment resuspension, which in turn leads to positive feedback to further growth and reproduction of vegetation (James and Barko, 1991; Madsen et al., 2001; Nepf et al., 2007). Reduced flow velocities favour finegrained sediments such as silt and clay to deposit within vegetation (Petticrew and Kalff, 1992). The extent of the flow and subsequent sedimentation, affected by vegetation, mainly depend on morphology, size and density of vegetation stems (Nepf, 1999; Jones et al., 2012). Increased fine-grained sedimentation within vegetation can lead to different deposition history and alter lakebed composition and properties such as grain size, water content, organic content, bulk density and cation exchange capacity etc. (Barko et al., 1991; Sand-Jensen, 1998). Sediment erodibility related to the incipient motion of sediment particles, when current or wave motions are applied, therefore changes. Removal of carp and subsequent vegetation growth can reduce sediment resuspension and enhance bottom sediment stability. However, to the authors' best understanding most studies documented the effects of carp on disturbing bottom sediments and damaging aquatic macrophytes. Very few studies reported how surficial bottom sediments, especially sediment sublayers, sediment bulk density and critical shear stress are affected by carp.

In this study, geophysical techniques and hydrodynamic methods are applied to monitor responses of bottom sediment stability after carp removal. The aim of this paper is to examine the changes of sediment structures, before and after carp removal. Specifically, bottom sediment bulk density and critical shear stress for causing sediment resuspension would be measured. Differences of macrophyte distribution and variations of sediment sublayers after carp removal would be quantified. By combing data obtained from geophysical and hydrodynamic measurements, the main source of bottom sediments degrading water quality can be identified.

\section{Study site}

Lake Wingra ( $\mathrm{N}^{\circ} 3^{\prime} 13^{\prime \prime}$, W $\left.89^{\circ} 25^{\prime} 11^{\prime \prime}\right)$ is located in south-central Wisconsin, USA, with a surface area of $1.3 \mathrm{~km}^{2}$ and mean water depth of $2.7 \mathrm{~m}$ (Fig. 1). Lake
Wingra is eutrophic and usually turbid due to increased suspended sediment concentrations (SSC). Beach closings are sometimes issued during summer months when dense blue-green algal blooms occur. Non-native carp were first introduced in the late 1800s. The water quality shortly degraded and macrophytes survived only in shallow waters of the lake. In 2005, a control experiment was conducted to monitor the responses of native macrophyte community in a carp-free environment. In the experiment, a 1-ha rectangular carp exclosure, with solid vinyl walls extending from the lake shoreline to a water depth of $2.9 \mathrm{~m}$, was built and all the carp were removed out of the exclosure. During the 3-year study period, it was observed that native macrophytes grew almost everywhere inside the exclosure $(\sim 0.6 \mathrm{~m}$ deeper than before the exclosure was built) and water became clearer in the exclosure, suggesting that carp plays an important role in disturbing bottom sediments. The carp exclosure was removed in September 2008. During the winters of 2007-2008 and 2008-2009, the Wisconsin Department of Natural Resources attempted to remove carp from Lake Wingra. Nearly 7000 carp were captured and taken out of the lake. According to the mark-recapture estimates, carp density in the lake declined by $51 \%$ (from 351 to $172 \mathrm{~kg} \cdot \mathrm{ha}^{-1}$ ).

\section{Methods and materials}

\section{Combined acoustic and electromagnetic (EM) wave-based geophysical techniques}

In order to characterize lake-bottom sediments, geophysical techniques, cost-effective and non-intrusive methods, are used in this study. Geophysical techniques provide continuous bottom mapping including bathymetry and sediment sublayers for substantially larger areas in comparison with traditional point-based sampling methods. In freshwater environments, acoustic signals are most extensively applied to image bathymetry and sediment sublayers (Damuth, 1980; Garcia et al., 2004). By examining the contrast of mechanical impedance (product of acoustic speeds in medium and bulk density of medium) and acoustic reflectivity, one can delineate the interface of different mediums, such as water-sediment, sand-clay layers or soft and hard patterns over lake floors (Nitsche et al., 2004; Lin et al., 2010). For example, sub-bottom profilers (SBP) have been employed to delineate lake bathymetry and sediment sublayers (Lin et al., 2009). Sidescan sonar (SSS) has been used to illustrate surficial sediment textures (Huvenne et al., 2002), sedimentary bedforms (Shawab et al., 1996) and objects such as shipwrecks over lake or sea floors (Ballard et al., 2002). Through successive surveys, changes of the lake floor and sublayer structures can thereby be determined, and the erosion or deposition patterns over lake bottoms are revealed (Nitsche et al., 2004). In addition, acoustic reflections from water-vegetation interface were used to detect aquatic vegetation, especially unseen submerged macrophytes (Maceina and Shireman, 1980), and measure 


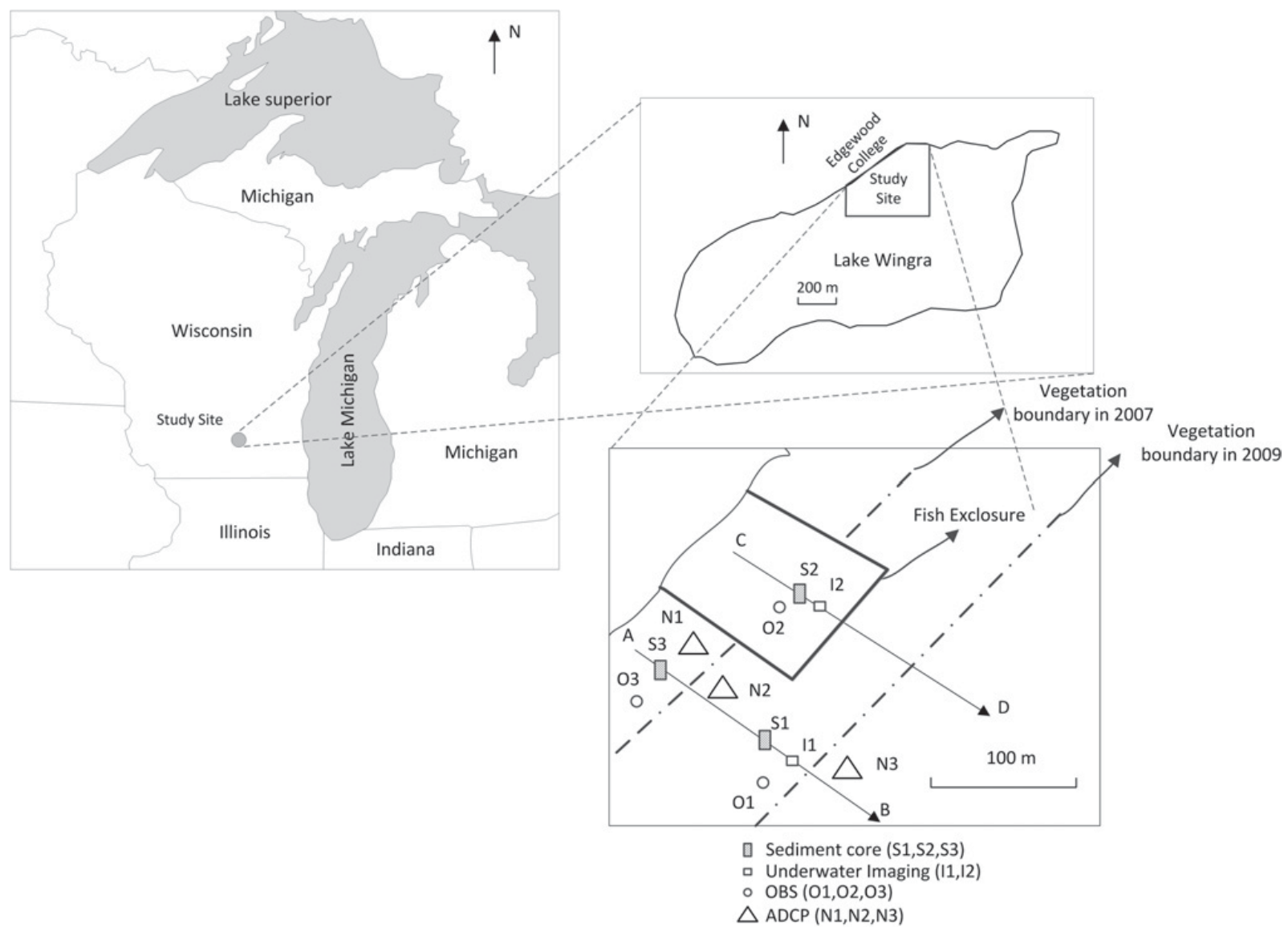

Fig. 1. Locations of the study site, Lake Wingra, survey lines and sampling locations.

the distribution and biomass of submerged aquatic vegetation (Sabol et al., 2002). However, acoustic signals have difficulties in penetrating coarse (e.g., sand and gravel) or gas-trapped sediments, glacial tills and bottom with aquatic vegetation growth because of low-energy transmission and signal scattering (Morang et al., 1997; Wilkens and Richardson, 1998; Sabol et al., 2002).

EM wave-based technique is another commonly used geophysical method (Sellmann et al., 1992). For example, ground-penetrating radar (GPR) images bathymetry and sublayer by distinguishing contrasts of dielectric properties in different mediums (Sambuelli and Bava, 2012). GPR performs well in coarse-grained sediments and vegetated environments, and can be a useful alternative when acoustic signals fail to map bathymetry and sediment sublayers (Annan and Davis, 1992; Lin et al., 2009). Nevertheless, the use of GPR is limited in high electrical-conductivity environments such as fine-grained sediments and water with high dissolved salt $(\mathrm{NaCl})$ due to significant energy attenuation (Annan, 2005). The combination of acoustic and EM wave-based geophysical techniques can provide complimentary information and a more complete picture of sediment subsurface (Lin et al., 2009).

In this study, acoustic-wave-based devices including SBP, SSS and EM wave-based GPR were used to investigate sediment sublayers and vegetation distribution.
A Trietch SeaKing SBP system with a GPS (Global Positioning System) receiver was mounted on a Zodiac boat to collect the bathymetry and sublayer information in November 2007 and 2009. The Tritech Seaking SBP system is a parametric echo-sounder, which emits two slightly different high-frequency signals $(\sim 100 \mathrm{kHz})$ to create high-frequency $(\sim 200 \mathrm{kHz})$ and low-frequency (LF) signals $(\sim 20 \mathrm{kHz})$ by adding or subtracting these two signals. The high-frequency signal provides the bathymetry information, whereas the LF signal can penetrate into bottom sediments to yield the sublayer information. Based on the signal frequency of $100 \mathrm{kHz}$, the SBP system has a vertical resolution of about $0.00375 \mathrm{~m}$ (quarter of the wavelength) by using the same acoustic speed of about $1500 \mathrm{~m} \cdot \mathrm{s}^{-1}$ in water and sediments (Santamarina et al., 2005). The reflected signals are emitted at the locations where mechanical impedance (product of density and acoustic speed in medium) significantly changes, i.e., at the interface of water and vegetation, water and sediments or different sediment types. The SBP system is therefore used to obtain the water depth, sediment sublayers (Lin et al., 2009) and the presence of submerged vegetation (Sabol et al., 2002). Unlike the SBP system to provide the bathymetry and sublayer information, the SSS system emits highfrequency and wide-angled acoustic signals to map substantial areas over lake floors. The backscattered 
signals can image the structures of small irregularities on the lake floors. Also, vegetation growth from the lake bottom can interfere with the SSS signals and cause acoustic shadows on the SSS data. The SSS manufactured by Trietch Co. was towed to about $0.5 \mathrm{~m}$ below the water surface, and operated at a frequency of $675 \mathrm{KHz}$ with $10 \mathrm{~m}$ range on each side of the track line, i.e., a swath of $20 \mathrm{~m}$, giving a sampling resolution (range/sampling points = $(2 \times 10) / 1396)$ of about $0.014 \mathrm{~m}$ and the coverage area of $20 \mathrm{~m}^{2} \cdot \mathrm{s}^{-1}$ with boat speed of about $1 \mathrm{~m} \cdot \mathrm{s}^{-1}$. Because vegetation was extensively found in littoral zones in Lake Wingra, acoustic signals to image bathymetry and sublayer was greatly affected. To map the areas with dense vegetation growth, we employed a pulseEkko 100 GPR system with a $400 \mathrm{~V}$ source and $100 \mathrm{MHz}$ antennae (central frequency of $\sim 50 \mathrm{MHz}$ ) to image bathymetry and sublayers. In terms of the central frequency of about $50 \mathrm{MHz}$ and the EM wave speed in water is $V_{\mathrm{EM}}^{\text {water }}=$ $3.3 \times 10^{7} \mathrm{~m} \cdot \mathrm{s}^{-1}$ and in sediments is $V_{\mathrm{EM}}^{\text {sed }}=10^{8} \mathrm{~m} \cdot \mathrm{s}^{-1}$, the GPR theoretical resolution in water is: $\operatorname{Res}^{\text {water }}=\left(V_{\mathrm{EM}}^{\text {water }} / 4 f\right)=\left(3.3 \times 10^{7} / 4.50 \times 10^{6}\right)=0.17(m)$, and in sediments is Res ${ }^{\mathrm{sed}}=0.50(\mathrm{~m})$. Sixty-four stacks per trace were adopted to reduce data smearing during continuous sublayer profiling (Lin et al., 2009). The geophysical measurements including SBP, SSS and GPR were conducted along several transects normal to the shoreline and extending from nearshore to offshore, in Lake Wingra. Some survey lines were located outside the fish exclosure, and some survey lines began inside the fish exclosure and then moved outside the fish exclosure. Two representative survey lines $\mathrm{AB}$ and $\mathrm{CD}$ are shown in Figure 1.

\section{Collection of ground-truth data}

The ground truth data used to validate the results from the remote geophysical techniques were collected by using several of the following methods. Following the ASTM Standard D1587-08 (2007), a thin-wall Shelby tube sampler with $7.3 \mathrm{~cm}$ inner diameter connected by several light aluminum tubes was deployed from a small boat to extract sediments from lake bottoms (Lin et al., 2009). The water depths were also obtained simultaneously. Sediment cores were collected in three locations, which are unvegetated areas outside the fish exclosure (S1), inside the fish exclosure (S2) and vegetated areas outside the fish exclosure (S3), respectively. In each location of sediment sampling, four sediment cores were collected and sealed, and then carefully transported upright to the laboratory to prevent disturbances on sediment structures. Two were used for analysis of sediment bulk density and the other two were for determination of critical shear stress, which is, the required shear stress to mobilize sediment particles from lake bottoms (McNeil et al., 1996). In the laboratory, sediment samples were extruded in every $5 \mathrm{~cm}$ segment from the Shelby tube by using an upright hydraulic press, which clamped the tube in place and pushed a circular piston up through the tube to remove the sediments.
The extracted sediments were weighted before and after they were oven-dried at $105^{\circ} \mathrm{C}$ for 3 days to obtain wet sediment bulk density $\rho_{\mathrm{w}}$ and percent water content $W$ by using following equations:

$$
\begin{gathered}
\rho_{\mathrm{w}}=\frac{m_{\mathrm{w}}}{V}, \\
W=\frac{m_{\mathrm{w}}-m_{\mathrm{d}}}{m_{\mathrm{w}}} \times 100,
\end{gathered}
$$

where $V$ is the volume of the sediment sample (=inner circular areas of the Shelby tube sampler $\times$ sample thickness), $m_{\mathrm{w}}$ is the mass of the wet sediment sample and $m_{\mathrm{d}}$ is the mass of the sediment sample after oven-dried.

Experiments to determine critical shear stress were conducted in a recirculating tilting flume at the Hydraulic Laboratory at the University of Wisconsin-Madison. A sediment core was inserted into the central line of the flume and was adjusted to level with the flume bottom at the onset of a resuspension test. When the test was conducting, an automated sediment erosion system (ASETS) was employed to push up the sediment core, maintain the sediment surface at the flume bottom and record the push-up distance (sediment erosion depths). The erosion rate $\left(\mathrm{cm} . \mathrm{s}^{-1}\right)$ can be calculated by sediment erosion depths dividing the corresponding elapsed time. According to the flow rate, water depth and flume slope, corresponding flume bottom shear stress can then be determined. The critical shear stress for initiation of erosion is defined as the bottom shear stress causing an erosion rate of $10^{-4} \mathrm{~cm} . \mathrm{s}^{-1}$ (McNeil et al., 1996; Lee et al., 2004). For details of the experimental procedures one can refer to Lee et al. (2004).

For imaging submerged macrophytes, an underwater camera, Atlantis Underwater Camera AUW-552, was attached to the SSS. The locations of sediment cores (S1, S2 and S3) and underwater images (I1: deeper water and I2: shallow water) are shown in Figure 1.

\section{Measurements of current speed and SSC}

In order to understand vegetation effects on circulation and sediment resuspension, an acoustic Doppler current profiler (ADCP) - Aqaudopp, manufactured by Nortek, and three optical backscattered sensors (OBS-3A manufactured by Campbell Scientific Inc., USA) were deployed to obtain current speeds and corresponding SSC in vegetated and unvegetated areas (Fig. 1). During summer 2008, the ADCP and three OBSs were deployed when the vegetation grew densely in the littoral zones of the lake. The ADCP was attached to a tripod at $0.5 \mathrm{~m}$ above the lake bottom and projected downwards to record current speeds near the lake bottom. The ADCP, placed in vegetated areas $(\mathrm{N} 1)$, interface between the vegetated and unvegetated areas (N2) and unvegetated areas (N3), collected in a continuous mode with a sampling rate of $1 \mathrm{~Hz}$, and measured three-dimensional velocity at every 

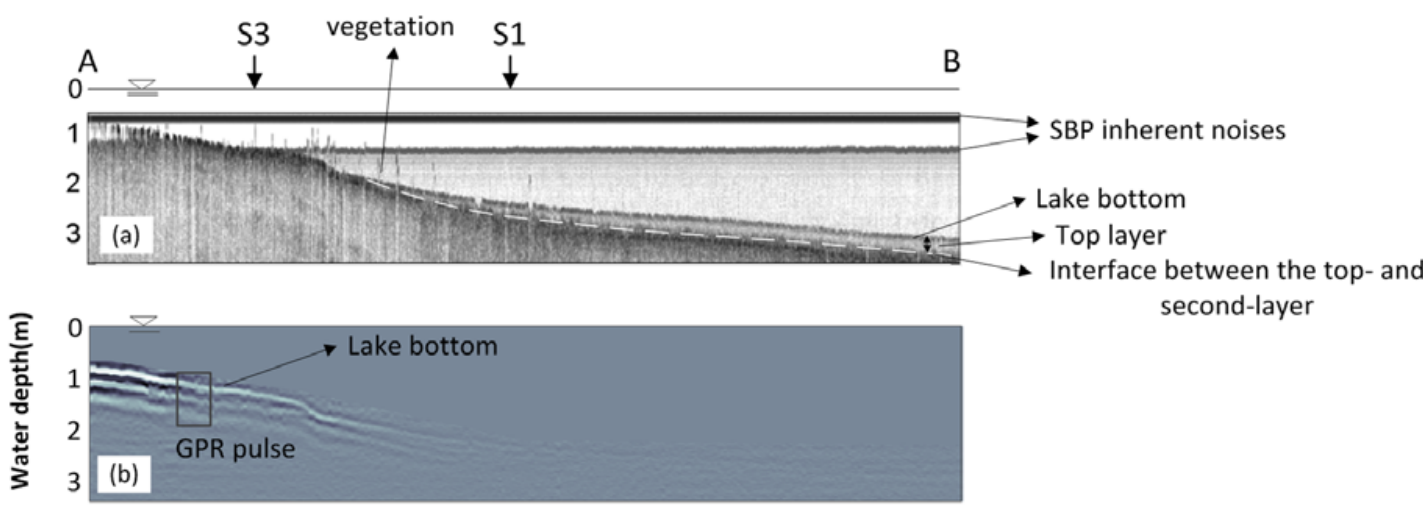
second-layer

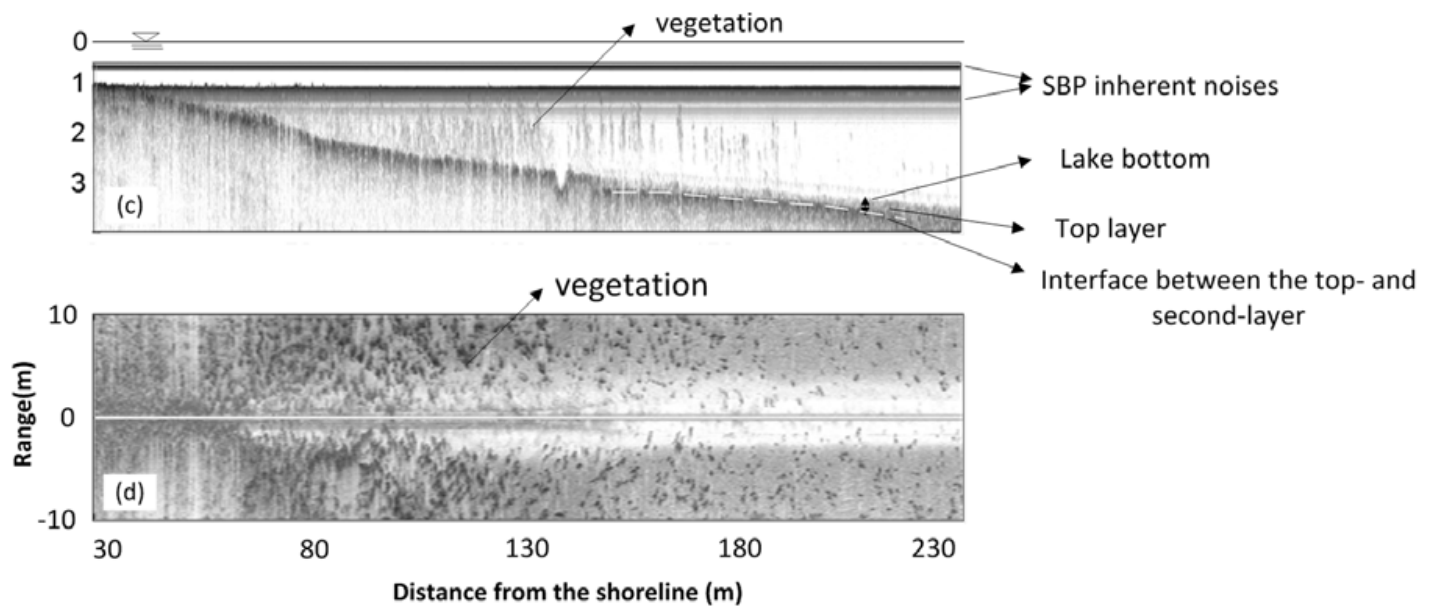

Fig. 2. SBP, GPR and SSS survey results for Line AB: (a) SBP LF data in Nov. 2007, (b) GPR data in Nov. 2007, (c) SBP LF data in Nov. 2009 and (d) SSS data in Nov. 2009. The dash-line in (a) and (c) means the interface between the top and second sediment sublayers, and the distance between the lake bottom and dash-line is the thickness of top-layer.

$5 \mathrm{~cm}$ interval. Three OBSs were installed at a height of $0.3 \mathrm{~m}$ above the lake bottom and deployed at N1, N2 and $\mathrm{N} 3$ to record $10 \mathrm{sec}$. data with a sampling rate of $25 \mathrm{~Hz}$ at every $30 \mathrm{sec}$. interval.

In addition, another measurement with three OBSs only was carried out in November 2007. The installation height and recording mode of the OBSs were similar to the measurements conducted in 2008 summer. Three OBSs were deployed in unvegetated areas outside the fish exclosure $(\mathrm{O} 1)$, vegetated areas inside the fish exclosure $(\mathrm{O} 2)$ and vegetated areas outside the fish exclosure (O3) (see Fig. 1). Following the calibration procedures suggested by Campbell Scientific Inc. (2011), the optical backscattered strengths recorded can then be converted to SSC.

\section{Results and discussions}

\section{Surficial sediment texture, sublayers and vegetation growth}

Firstly, the surficial sediment texture, sublayer and vegetation growth before and after carp removal are examined. Figure 2 shows a selected cross-shore transect (Line AB) outside the fish exclosure for SBP LF results,
GPR and SSS data obtained in November 2007 (before carp removal) and 2009 (after carp removal). The inherent noises generated from the SBP transducer were shown at constant locations on echograms (see notations in Fig. 2). For the SBP plot, the darker color represents stronger reflections, i.e., larger mechanical impedance, which may be the locations at the interfaces of vegetation and water, water and sediments, or different sediment types. The Shelby tube sampler gave the depth of sediment bottoms between 1 and $3.5 \mathrm{~m}$, and thus the first acoustic peak (beside the SBP inherent noises) forming a continuous, gradually deepening and strong acoustic reflection line between these ranges indicates the lake bottom (see notations in Figs. 2(a) and (c)). In contrast with the lakebottom reflections, some weak reflections appeared between lake surfaces and lake bottoms are due to submerged macrophytes, which attenuate acoustic signals, and may prevent acoustic signals from imaging sublayers (Sabol et al., 2002). In 2007, the GPR data used as a complementary alternative to image sublayers were collected with the SBP along Lines AB and CD. Figures 2(b) and 3(b) provide the GPR results, and the $y$-axis represents the depth converted by using the EM wave speed in water $\left(V_{\mathrm{EM}}^{\text {water }}=3.3 \times 10^{7} \mathrm{~m} \cdot \mathrm{s}^{-1}\right)$. Three parallel lines are observed, and the first line from the water surface is the lake bottom (see the GPR pulse box in Figs. 2(b) and 

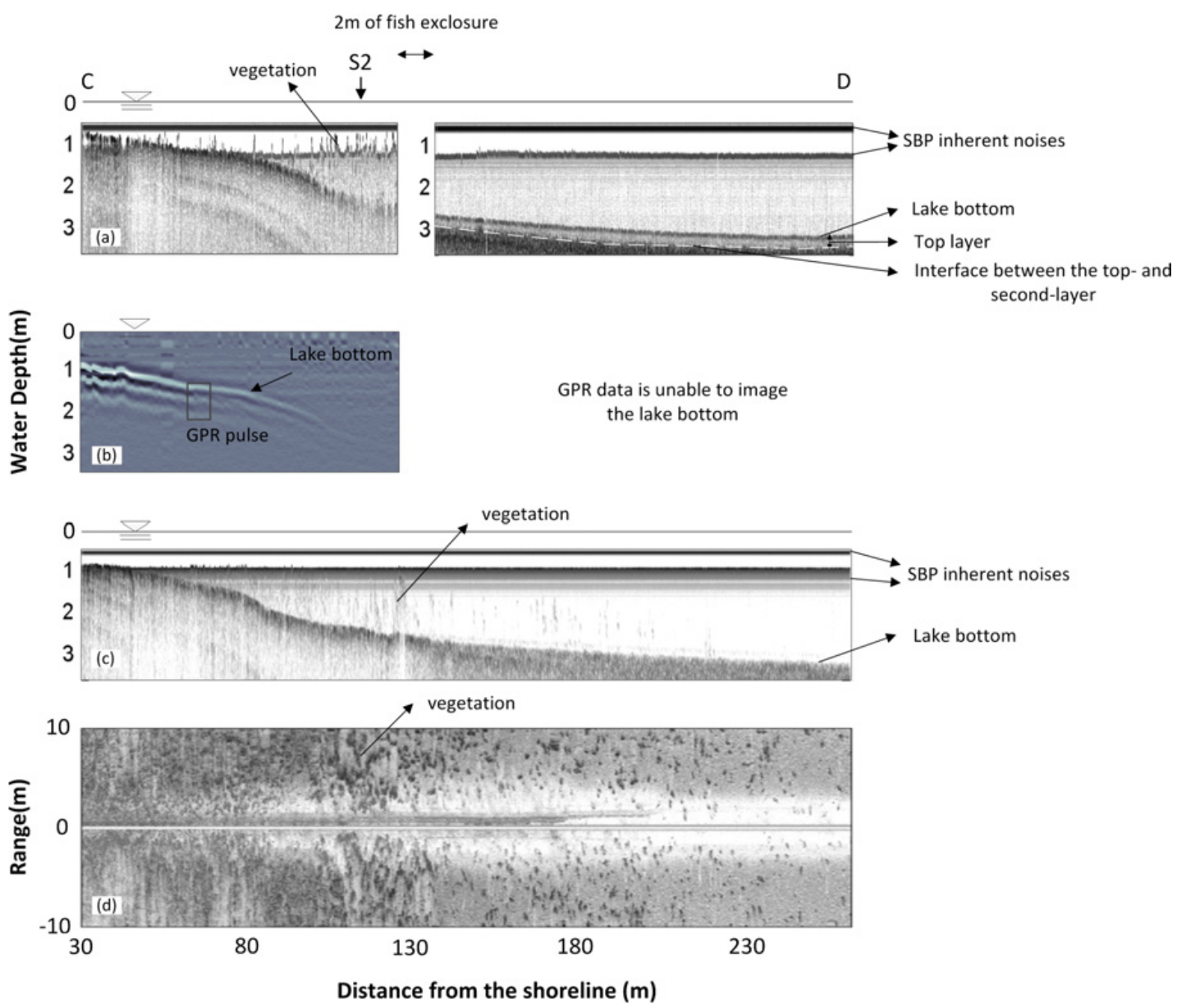

Fig. 3. SBP, GPR and SSS survey results for Line CD: (a) SBP LF data in Nov. 2007, (b) GPR data in Nov. 2007, (c) SBP LF data in Nov. 2009 and (d) SSS data in Nov. 2009.

3(b)) with the water depth less than $2 \mathrm{~m}$. The distance between each line is approximately $0.25 \mathrm{~m}$ (based on $\left.V_{\mathrm{EM}}^{\text {water }}\right)$ close to the GPR resolution $\left(\operatorname{Res}^{\text {water }}=0.17 \mathrm{~m}\right.$ ), and these lines are probably not actual layers but from the side lobes of the reflected GPR wavelet (Arcone et al., 2003). EM waves attenuated fast so that lake bottom in deep water (depth $>2 \mathrm{~m}$ ) was undetected on GPR results. Fast decaying of EM waves may be attributed to the high chloride levels in the lake. The application of road salt is crucial for road maintenance in winter, but it also elevates chloride levels in Lake Wingra when the road salt is carried into the lake by rains and spring snow-melts. From 1960 to 2009, the chloride levels have been increasing from $10 \mathrm{mg} . \mathrm{L}^{-1}$ to $90 \mathrm{mg} . \mathrm{L}^{-1}$ (Wenta et al., 2009). Although no information of water conductivity was available during the survey periods, based upon the water conductivity $\left(=500 \mu \mathrm{s} . \mathrm{cm}^{-1}\right)$ collected by UW-Madison Center for Limnology in the summer (http://lter.limnology.wisc.edu/ about/lakes), the skin depth $\delta$, which means the GPR signal amplitude drops to $1 / e$ (about one-third) of its original value, can be estimated by (Burger et al., 2006):

$$
\delta=\sqrt{\epsilon_{\mathrm{r}}} /(1685 \sigma)
$$

where $\varepsilon_{\mathrm{r}}$ is the relative dielectric permittivity and $\sigma$ is the water conductivity. For water $\varepsilon_{\mathrm{r}}=80$ and $\sigma=500\left(\mu \mathrm{S} . \mathrm{cm}^{-1}\right)$, the skin depth $\delta$ estimated is $0.11 \mathrm{~m}$, i.e., the GPR signal decayed substantially in Lake Wingra.

The underwater images shown in Figure 4(a) confirm the presence of submerged macrophytes, identified as Myriophyllum spicatum, commonly seen in Lake Wingra (Trebitz et al., 1993). In 2007, most submerged macrophytes grew up to about $2 \mathrm{~m}$ in water depth and approximately $100 \mathrm{~m}$ from the shoreline; while submerged macrophytes were found at a water depth of about $3 \mathrm{~m}$ and approximately $230 \mathrm{~m}$ from the shoreline in 2009 . Figure 2 also presents that the numbers of signal reflections from submerged vegetation in 2009 were more than those in 2007 , i.e., denser vegetation appeared in 2009. Similarly, the SSS plots show acoustic reflections and shadows from submerged vegetation. As water depth increases, decreasing density of small dots indicates less vegetation growth because of less light availability in deeper water. The acoustic beams are like light sheets, and vegetation stems block acoustic signals, generating acoustic shadows behind these stems. Some small dots without shadows possibly represent very short-stemmed submerged vegetation. Additionally, the SBP data reveals that there was a visible layer (called top-layer afterwards) underneath the lake bottom at the locations between 90 and $250 \mathrm{~m}$ (less vegetation was found) from the shoreline 


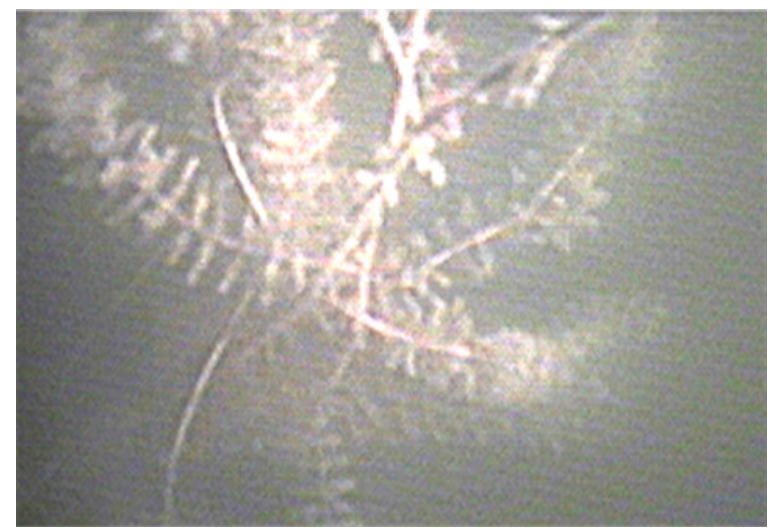

(a)

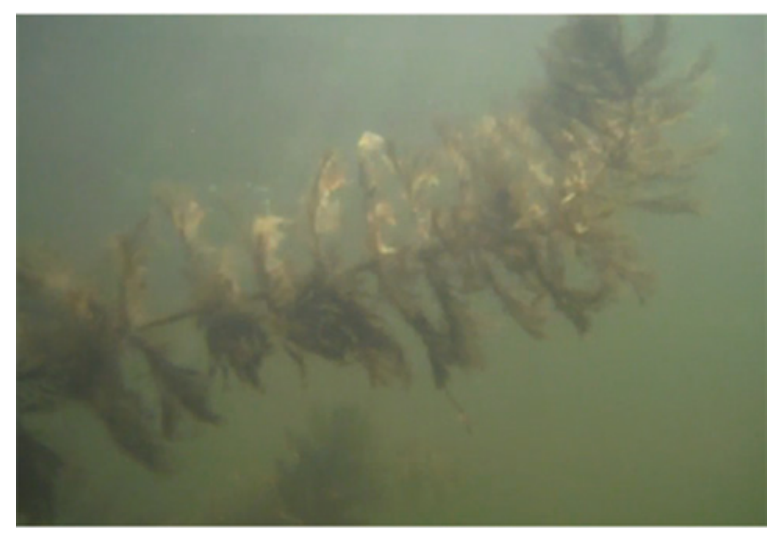

(b)

Fig. 4. Underwater images at (a) location I1 and (b) location I2.

(Fig. 2(a)). The apparent color differences between the top-layer and underneath layer possibly mean significant variations of sediment bulk density and acoustic speed in mediums between the two layers. Dash-line in Fig. 2(a) represents the interface between the top and second sediment layers. The top-layer became thicker at deeper water where submerged macrophytes were less. Density of macrophytes influences current speeds and subsequent sedimentation rates which are possibly associated with the thickness of the top sediment layer (Sand-Jensen, 1998). By assuming the acoustic speed of $1500 \mathrm{~m} \cdot \mathrm{s}^{-1}$ in sediments, the thickness of top-sublayer was estimated to about $0.5 \mathrm{~m}$ at a water depth of $\sim 3 \mathrm{~m}$ (point $\mathrm{B}$ ), i.e., distance between locations of the first and second acoustic peaks under the lake bottom. After more than half of carp were removed in 2009, the top-layer became blurred which meant that contrast of mechanical impedance between the top and second sediment sublayers decreased. The top layer in 2009 could only be found between 140 and $220 \mathrm{~m}$ from the shoreline and was thinner than that in 2007 (see dash-line in Fig. 2(c)). Since acoustic speeds in sediments vary over a relative narrow range $\left(1400-1600 \mathrm{~m} . \mathrm{s}^{-1}\right.$, Lin et al., 2009), one possible explanation is that sediment bulk density between the top and second layers turned similar.

Figure 3 displays the SBP and SSS data across the fish exclosure (Line CD) in 2007 and 2009. As mentioned in the section "Study Site", abundant vegetation grew almost everywhere inside the fish exclosure (carp-free environment). Therefore, the SBP data show dense acoustic reflections in the water column inside the fish exclosure (see Fig. 3(a), 30-120 $\mathrm{m}$ from the shoreline). Outside the fish exclosure (beyond $120 \mathrm{~m}$ from the shoreline), in contrast, a visible layer similar to that shown in Fig. 2a was observed (see dash-line in Fig. 3(a)). In 2009, the visible layer was very blurred similar to Line $A B$, and vegetation grew to deeper water (depth $\sim 2.5-3 \mathrm{~m}$ ). The SSS data and underwater image (Fig. 4(b)) affirms the presence and extending range of the submerged macrophytes. Several other survey lines also show that vegetation grew to deeper water, and a visible sediment layer became indistinct in 2009 .

\section{Bulk density and critical shear stress}

Sediment cores were collected from three locations S1, S2 and S3 for determination of sediment bulk density and critical shear stress (Fig. 1). Vegetation characteristics for the three locations were S1 (unvegetated areas outside the fish exclosure), S2 (vegetated areas inside the fish exclosure) and S3 (vegetated areas outside the fish exclosure), respectively. The vertical profiles $(0-0.3 \mathrm{~m}$ below bottom sediments) of sediment bulk density in 2007 and 2009 are provided in Figure 5. In 2007, considerable differences of sediment bulk density were found among S1, S2 and S3. For S1 (unvegetated and sampled at the visible layer), specific gravity of sediments, i.e., ratio of wet bulk density of sediments to water density $\left(=1 \mathrm{~g} . \mathrm{cm}^{-3}\right)$ in the first 0.30 $\mathrm{m}$ sediments ranged between 1.1 and 1.13. On the other hand, specific gravity of sediments in S3 (vegetated areas) varied between 1.16 and 1.20 , and generally increased with sediment depths (depth below sediment bottom). Sediment bulk density in vegetated areas (S3) was greater than that in unvegetated areas (S1), namely, bottom sediments in vegetated areas were more consolidated and stable as many studies have reported (Fonseca, 1996; Madsen et al., 2001; Cronin et al., 2006). The values of wet bulk density along sediment depths ranked as $\mathrm{S} 2>\mathrm{S} 3>\mathrm{S} 1$, corresponding to the inverse disturbance level by external drivers such as carp, waves or currents. The fish exclosure (location of S2) provides carp-free environment, and its solid vinyl walls also reduce wave energy and current speed. Thus, the least disturbed environment in S2 resulted in the greatest sediment bulk density, i.e., the most consolidated sediments among S1, S2 and S3. Percent water contents following the inverse order of wet bulk density positioned as: $\mathrm{S} 1(80-84 \%)>\mathrm{S} 3(71-77 \%)>\mathrm{S} 2$ $(68-70 \%)$. In 2009, vegetation grew extending to offshore, and S1 where there was no vegetation growth in 2007 was in vegetated areas. The specific gravity of sediments at S1 and S2 became similar, and increased as sediment depths became deeper. Compared with the data from 2007, the specific gravity of sediments in S1 increased in 2009 as a result of vegetation growth to reduce the effects of wave energy and current speeds. However, the carp exclosure 


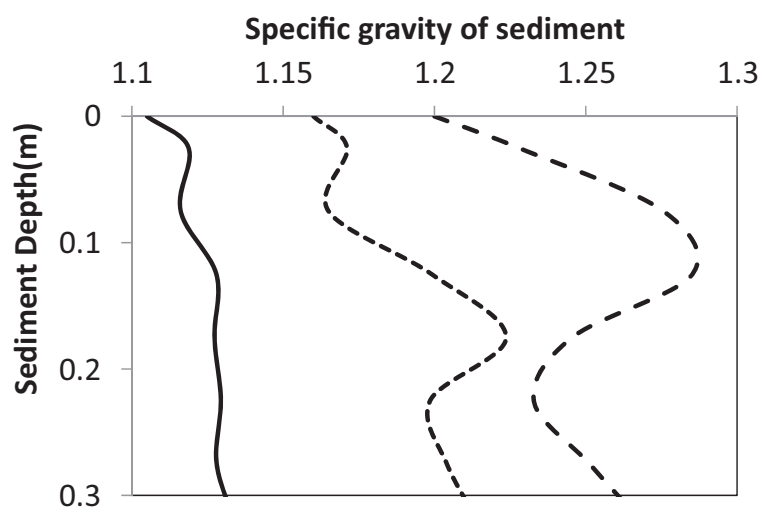

(a)

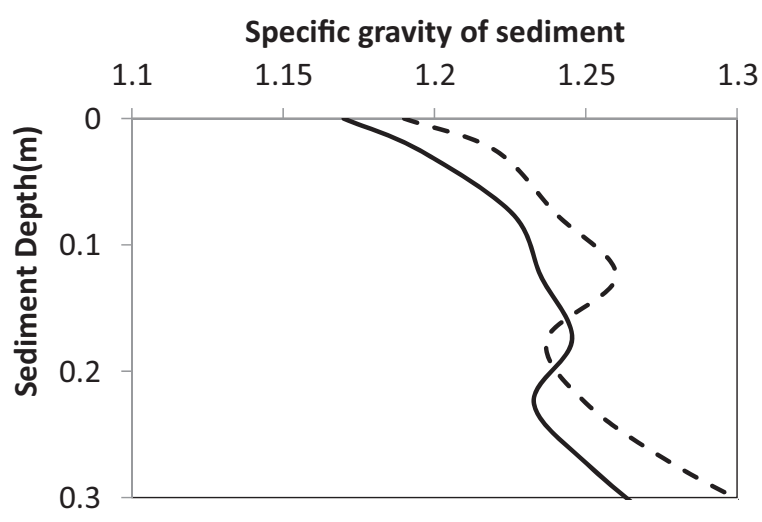

(b)

Fig. 5. Specific gravity of sediment with sediment depths at different locations (S1: —, $\mathrm{S} 2$ : $\quad--$ and $\mathrm{S} 3$ : -...-). (a) November 2007 and (b) November 2009.

was removed in 2008, and since then the S2 location, where the fish exclosure was previously installed, was not well-protected. Bottom sediments were influenced by wave or current motions after the exclosure removal and became slightly loose from 2007 to 2009 .

In 2007, critical shear stress at S1, S2 and S3 increased with sediment depths showed pronounced differences owing to different vegetation patterns and hydrodynamic conditions (Fig. 6). The magnitude of the critical shear stress that gave: $\mathrm{S} 2>\mathrm{S} 3>\mathrm{S} 1$, proportional to sediment bulk density, agreed with the formula of Mehta and Parchure (2000). Thus, following the same trends of sediment bulk density, critical shear stress increased as sediment depths kept increasing. Critical shear stress in vegetated areas (S2 and S3) was found to be greater than that in unvegetated areas (S1). After vegetation grew in S1, critical shear stresses in S1 became larger at different sediment depths, i.e., at the lake floor (sediment depth of 0 ) from $0.026 \mathrm{~Pa}$ in 2007 to $0.035 \mathrm{~Pa}$ in 2009 , and at a sediment depth of $0.30 \mathrm{~m}$ from $0.31 \mathrm{~Pa}$ in 2007 to $0.48 \mathrm{~Pa}$ in 2009. The critical shear stress increase by about $40 \%$ from 2007 to 2009 can be attributed to carp removal and vegetation growth, which increases sedimentation rates and stabilizes bottom sediments (Fonseca, 1996; Madsen et al., 2001). For $\mathrm{S} 2$, no significant change on critical shear stress was observed from 2007 to 2009.

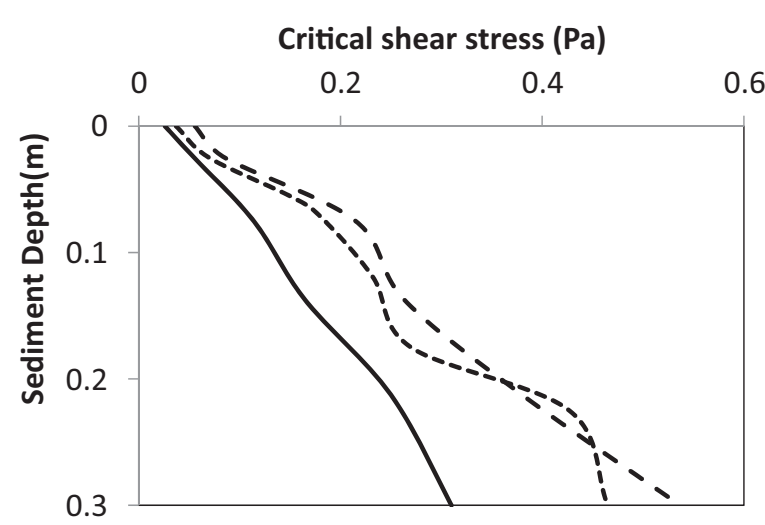

(a)

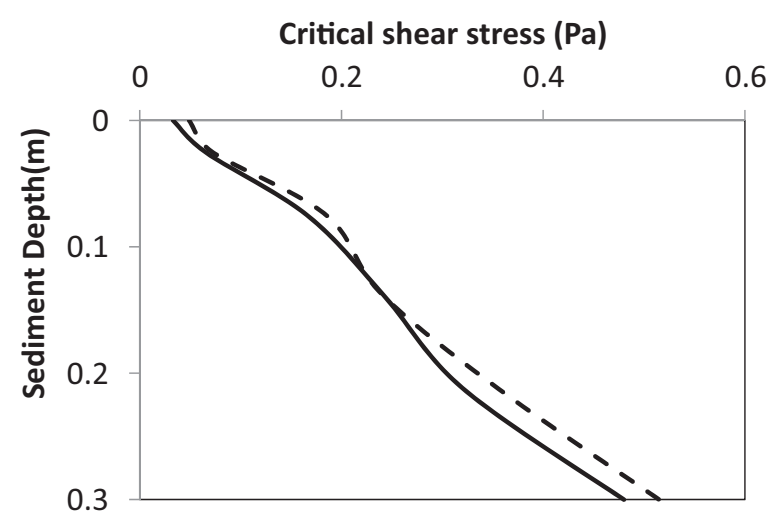

(b)

Fig. 6. Critical shear stress with sediment depths at different locations (S1: —, S2: - - - and S3: - - - - ) . (a) November 2007 and (b) November 2009.

\section{Vegetation presence, current speeds and sediment resuspension}

Figure 7 presents wind speeds, directions and SSC data collected in a wind event in November 2007. Due to lack of direct measurements, wind speeds and directions were obtained from the department of atmospheric and oceanic sciences at the University of Wisconsin-Madison. Relative strong wind $\left(U_{10}>8 \mathrm{~m} . \mathrm{s}^{-1}\right)$ from west was observed from the afternoon on 14 November to noon on 15 November 2007 (Figs. 7(a) and (b)). At the same time, the SSC began to increase, i.e., sediment resuspension occurred on 14 November 2007. Obviously, SSC $\left(\sim 600 \mathrm{mg} . \mathrm{L}^{-1}\right)$ was much larger in the unvegetated areas than that $(\sim 45$ mg. $\mathrm{L}^{-1}$ ) in vegetated areas (Figs. 7(c) and (d)). Because of smaller critical shear stress (see the previous section) and larger wind-induced wave and current motions in unvegetated areas, the fluffy and loose sediment layer (specific gravity between 1.10 and $\sim 1.13$ ) in unvegetated areas was easily resuspended and possibly the main source for bottom sediments in suspension in water, Also, due to protection of the fish exclosure, the inside areas were not disturbed by wave motions, and SSC was much lower $(<5$ $\left.\mathrm{mg} . \mathrm{L}^{-1}\right)$ than that outside the fish exclosure. SSC started to decrease around noon of 15 November, 2007, i.e., sediment supplies from lake floors were reduced. 

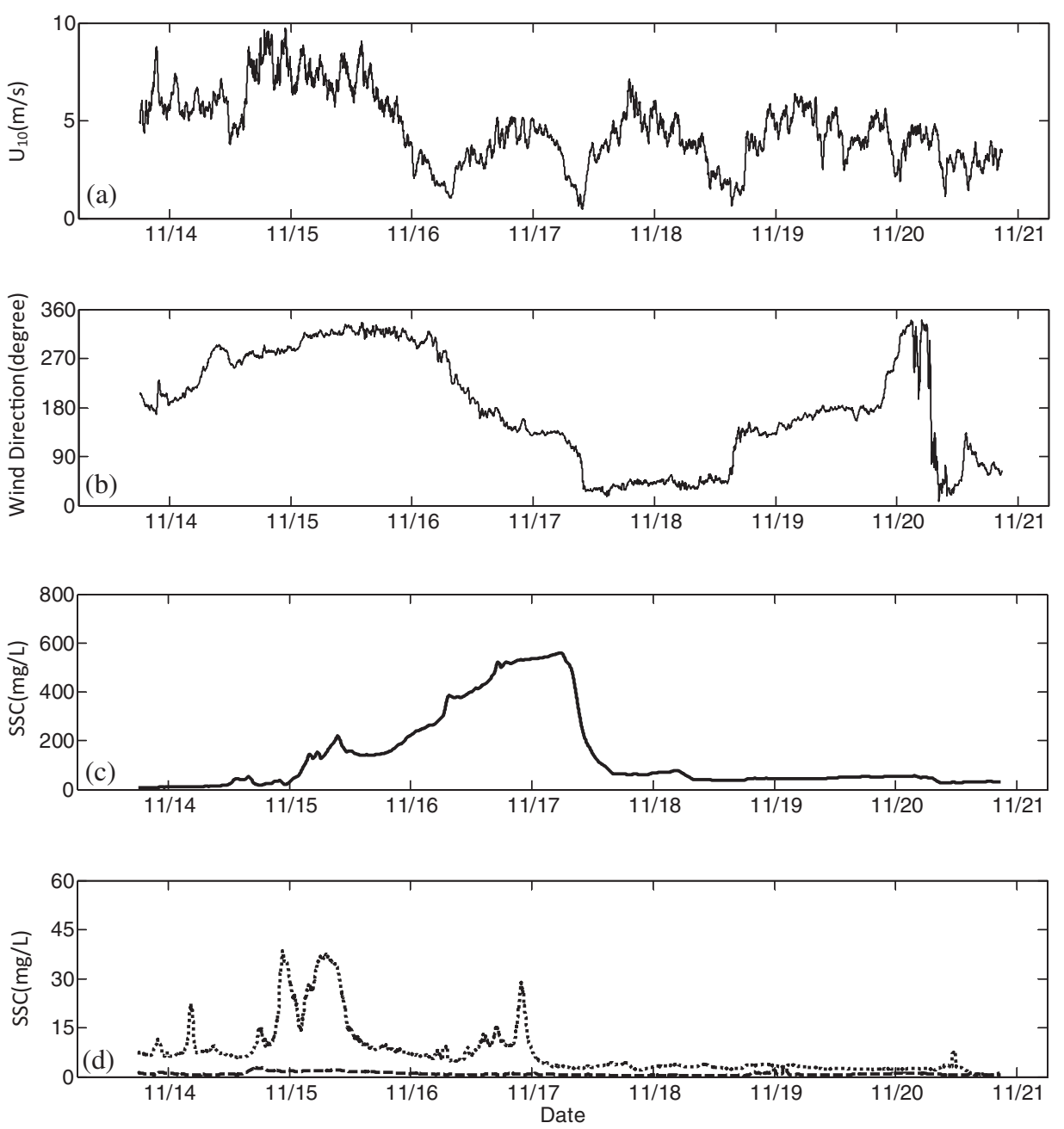

Fig. 7. Time series of (a) wind speed $U_{10}$, (b) wind direction (0 degree is from north and 90 is from east), (c) SSC in O1 ( $\longrightarrow$ ) and (d) SSC in O2 (- - -) and O3 (-..-.) in November 2007.

Interestingly, SSC in unvegetated areas drastically increased from 16 November 2007, and reached peaks on 17 November 2007. During this period, wind speeds $U_{10}$ declined and were less than $5 \mathrm{~m} \cdot \mathrm{s}^{-1}$ and from southeast $\left(135^{\circ}\right)$ where fetch length was too $\operatorname{small}(<300 \mathrm{~m})$ to produce prominent wave motions and subsequently sediment resuspension. The possible explanation is that increases in sediment concentrations in unvegetated areas were not from local bottom sediment resuspension (vertical transport) but brought from other places through horizontal sediment transport. Since vegetation slows down current speeds, horizontal sediment transport that induces increasing SSC may not be obvious in vegetated areas. Winds began to decline from midnight of 17 November, 2007, approached close to zero at around noon, and accompanying wind-induced wave motions and circulations were lessened as well. As a result of decreasing momentum in the water column, SSC was abruptly reduced, which meant that most of sediment particles were settling down at this moment. Mean grain size $d_{50}$ of bottom sediments in unvegetated areas were $0.031 \mathrm{~mm}$, classified as silt. Based upon the formula of Cheng (1997), settling velocity was estimated as $0.068 \mathrm{~cm} . \mathrm{s}^{-1}$, and settling time was $72 \mathrm{~min}$ at the water depth of $3 \mathrm{~m}$. Thus, as long as momentum to support sediment particles suspended in the water column disappeared, sediment transport would cease and suspended sediments would then deposit in very short time. After 17 November 2007, wind speeds $U_{10}$ were not more than $7 \mathrm{~m} . \mathrm{s}^{-1}$, and sediment resuspension was not observed in the measurement period. The results show that during a one-day wind event, sediments from the fluffy layer in unvegetated areas were resuspended and entrained into the water column, and remained suspended in the water column for 2 days.

During the summer of 2008, ADCP and OBS were deployed in three locations (inside vegetation, interface of vegetation and open water and outside vegetation) at around the same time. Three OBSs were installed to measure SSC in the three locations, and the ADCP was placed in one location to measure current speeds for $5 \mathrm{~min}$. and then moved to the other location. Figure 8 


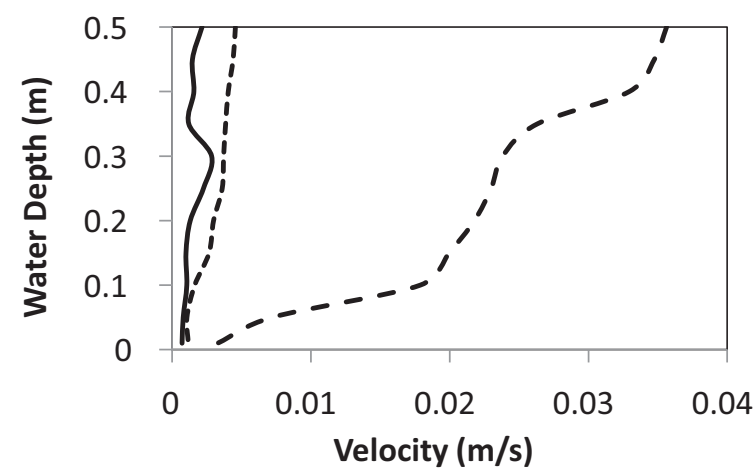

(a)

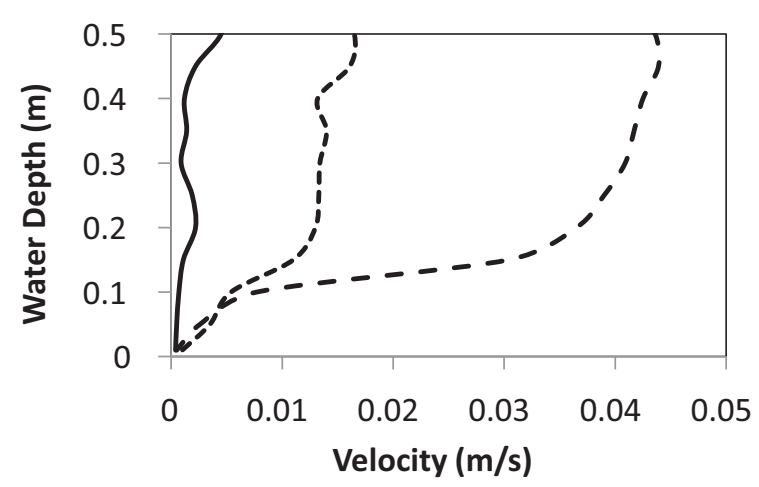

(b)

Fig. 8. Horizontal current velocity at different locations (N1: — N2: - - - and N3: -...-) collected in summer 2008. (a) wind speed $U_{10}$ of $3.13 \mathrm{~m} . \mathrm{s}^{-1}$, direction of $308^{\circ}$ and (b) wind speed $U_{10}$ of $4.83 \mathrm{~m} . \mathrm{s}^{-1}$, direction of $275^{\circ}$.

presents profiles of horizontal velocity in abovementioned three locations in two different cases (case (a): wind speed $U_{10}$ of $3.13 \mathrm{~m} . \mathrm{s}^{-1}$, wind direction of $308^{\circ}$, and case (b): wind speed $U_{10}$ of $4.83 \mathrm{~m} . \mathrm{s}^{-1}$, wind direction of $\left.275^{\circ}\right)$. The corresponding SSC (mg. $\left.\mathrm{L}^{-1}\right)$ inside vegetation, at the interface, and outside vegetation in the two cases are: case (a) 3.06, 5.12 and 18.74 and (b) 4.15, 13.04 and 25.17. Both current speeds and SSC increased in areas with less dense vegetation as previous studies indicated (James and Barko, 1994; Madsen et al., 2001). In case (a), $24 \mathrm{~h}$ averaged weather conditions prior to data collection were: wind direction varied and small averaged wind speeds $U_{10}\left(\sim 2.32 \mathrm{~m} . \mathrm{s}^{-1}\right)$. The relatively calm weather conditions led to almost no sediment resuspension. For case (b), wind started to blow $22 \mathrm{~h}$ before data collection. The $22 \mathrm{~h}$ averaged wind direction and speeds $U_{10}$ prior to data collection were $243^{\circ}$ and $5.05 \mathrm{~m} . \mathrm{s}^{-1}$. However, the relative windy conditions in case (b) did not cause significant sediment resuspension (similar SSC as in case (a)). The results possibly imply that when carp began to be removed during the winter of 2008, bottom sediments gradually consolidated and were hardly remobilized even in relatively windy days.

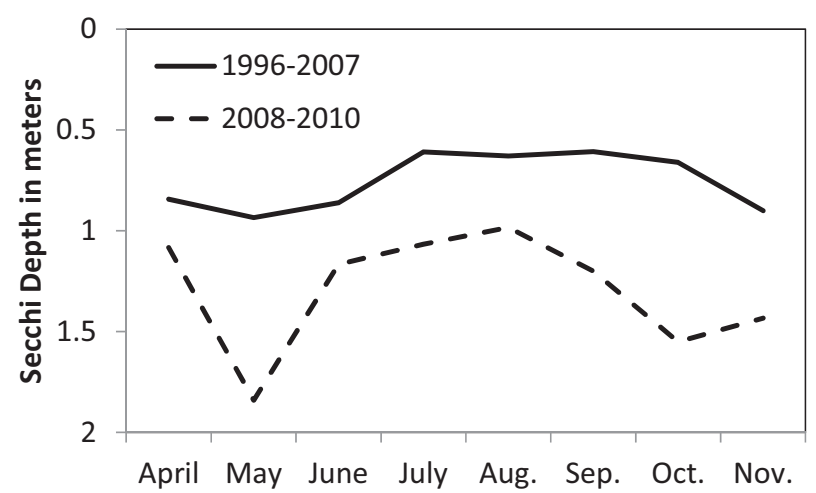

Fig. 9. Secchi disc data of Lake Wingra from 1996 to 2010. The carp were removed (51\% removal) during March 2008 and 2009. [Database]http://lter.limnology.wisc.edu/data/filter/5640.

\section{Water clarity, carp removal, vegetation growth and sediment properties}

The North Temperate Lakes Long-Term Ecological Research program routinely measures Secchi depth data twice per month in Lake Wingra. Figure 9 displays that the averaged Secchi depth during 2008-2010 was more than that during 1996-2007, i.e., water became clearer after the removal of carp during the winters of 2008 and 2009. Improved water quality could be attributed to the reduction of sediment resuspension and algae growth. The removal of carp led to the abundance of submerged macrophytes and consolidation of sediment bottoms especially in deep water. In deep water, vegetation growth dampened wave energy and current velocity, and thus increased sedimentation rates which raised sediment bulk density by average $10 \%$ and critical shear stress by approximately $40 \%$. In turn, the original fluffy and loose sediment layer became more consolidated and stable, and thus wind events were unable to remobilize bottom sediments and release nutrients from bottom sediments as easily as before.

\section{Summary}

Based upon geophysical measurements, ground-truth data and in situ sediment data, it is revealed that before carp were removed, a fluffy sediment layer was found in unvegetated areas, and easily resuspended during windy days. The data show that a one-day wind event could lead to sediment suspension in the water column for 2 days. The fluffy sediment layer that arose from carp activities could be the main source of sediment resuspension to degrade water quality, and subsequently reduce vegetation growth. After carp were removed (51\% removal), the original fluffy sediment layer became more consolidated and stable (greater sediment bulk density and critical shear stress), and the chances of sediment resuspension were reduced. Water became clearer and vegetation thus grew in the deep water. Meanwhile, vegetation can also provide 
inherent drag to reduce wave motions and flow velocity which can disturb bottom sediments. The positive feedback mechanism between vegetation and water quality could lead to further vegetation growth in deeper water, and Lake Wingra began to turn into a clear water state after carp removal.

Acknowledgements. We thank Mr. Richard Lathrop for his insightful comments and suggestions. We acknowledge Center for Limnology at University of Wisconsin-Madison, and the Wisconsin Department of Nature Resources for their continuous fieldwork support. We appreciate Nortek, USA for providing an Aquadopp for field measurements. We also thank Anna Grant Birge Award for providing funding.

\section{References}

Annan A.P., 2005. Ground penetrating radar. In: Butler K. (ed.), Near Surface Geophysics, Society of Exploration Geophysicists, Tulsa, 357-438.

Annan A.P. and Davis J.L., 1992. Design and development of a digital ground penetrating radar system. In: Pilon J. (ed.), Ground Penetrating Radar, Geological Survey of Canada Special Paper, Vol. 90 (4), Canada Communication Group, Ottawa, 15-23.

Arcone S.A., Peapples P.R. and Liu L., 2003. Propagation of a ground-penetrating radar (GPR) pulse in a thin-surface waveguide. Geophysics, 68, 1922-1933.

ASTM Standard D1587-08, 2007. ASTM D1587-08 Standard Practice for Thin-Walled Tube Sampling of Soil for Geotechnical Purposes, ASTM International, West Conshohocken, PA.

Ballard R.D., Stager L.E., Master D., Yoerger D., Mindell D., Whitcomb L.L., Singh H. and Piechota D., 2002. Iron Age shipwrecks in deep water off Ashkelon, Israel. Am. J. Archaeol., 106, 151-168.

Barko J.W., Gunnison D. and Carpenter S.R., 1991. Sediment interaction with submersed macrophyte growth and community dynamics. Aquat. Biol., 41, 41-65.

Breukelaar A.W., Lammens E.H.R.R., Breteler J.G.P.K. and Tatrai I., 1994. Effects of benthivorous bream (Abramis brama) and carp (Cyprinus carpio) on sediment resuspension and concentrations of nutrients and chlorophyll a. Freshwater Biol., 32, 113-121.

Burger H.R., Sheehan A.F. and Jones C.H., 2006. Introduction to Applied Geophysics: Exploring the Shallow Subsurface, W. W. Norton \& Company, New York, 554 p.

Cahoon W.G., 1953. Commercial carp removal at Lake Mattamuskeet, North Carolina. J. Wildlife Manage., 17, 312-317.

Campbell Scientific Inc., 2011. OBS-3A Turbidity and Temperature Monitoring System-Operator's Manual, Campbell Scientific Inc., Logan, 58 p.

Cheng N.S., 1997. Simplified settling velocity formula for sediment particle. J. Hydraul. Eng., 123, 149-152.

Crivelli A.J., 1983. The destruction of aquatic vegetation by carp. A comparison between Southern France and the United States. Hydrobiologia, 106, 3741.

Cronin G., William M.L. Jr. and Schiehser M.A., 2006. Influence of freshwater macrophytes on the littoral ecosystem structure and function of a young Colorado reservoir. Aquat. Bot., 85, 37-43.

Damuth J.E., 1980. Use of high-frequency $(3.5 \mathrm{kHz}-12 \mathrm{kHz})$ echograms in the study of near-bottom sedimentation processes in the deep-sea: a review. Mar. Geol., 38, 51-75.

Fonseca M., 1996. The role of seagrasses in nearshore sedimentary processes: a review. In: Nordstrom K. and Roman C.T. (eds.), Estuarine Shore: Evolution, Environments and Human Alternations, John Wiley \& Sons, London, 261-286.

Garcia G.A., Garcia-Gil S. and Vilas F., 2004. Echo characters and recent sedimentary processes as indicted by highresolution sub-bottom profiling in Ria de Vigo, NW Spain. Geo. Mar. Lett., 24, 32-45.

Hamilton D.P. and Mitchell S.F., 1997. An empirical model for sediment resuspension in shallow lakes. Hydrobiologia, 317, 209-220.

Havens K.E., 1991. Fish-induced sediment resuspension: effects on phytoplankton biomass and community structure in a shallow hypereutrophic lake. J. Plankton Res., 13, 1163 1176.

Huvenne V.A.I., Blondel P.H. and Henriet J.-P., 2002. Textural analyses of sidescan sonar imagery from two mound provinces in the Porcupine Seabight. Mar. Geol., 189, 323-341.

James W.F. and Barko J.W., 1991. Influences of submersed aquatic macrophytes on zonation of sediment accretion and composition, Eau Galle Reservoir, Wisconsin. Technical Reports A-91-1, US Army Engineer Waterways Experiment Station, Vicksburg, MS, 23 p.

James W.F. and Barko J.W., 1994. Macrophyte influences on sediment resuspension and export in a shallow impoundment. Lake Reserv. Manage., 10, 95-102.

Jeppesen E., Jensen J.P., Kristensen P., Søndergaard M., Mortensen E., Sortkjaer O. and Olrik K., 1990. Fish manipulation as a lake restoration tool in shallow, eutrophic, temperature lakes 2: threshold levels, longterm stability and conclusions. Hydrobiologia, 200/201, 219-227.

Jeppesen E., Søndergaard M. and Christoffersen K. (eds.), 1998. The Structuring Role of Submerged Macrophytes in Lakes, Ecological Series, Vol. 131, Springer-Verlag, New York, $423 \mathrm{p}$.

Jones J.J., Collins A.L., Naden P.S. and Sear D.A., 2012. The relationship between fine sediment and macrophyte in rivers. River Res. Appl., 28, 1006-1018.

King D.R. and Hunt G.S., 1967. Effect of carp on vegetation in a Lake Erie marsh. J. Wildlife Manage., 31, 181-188.

Koch E.W., 2001. Beyond light: physical, geological, and geochemical parameters as possible submersed aquatic vegetation habitat requirements. Estuaries, 24, 1-17.

Lee C., Wu C.H. and Hoopes J.A., 2004. Automated sediment erosion testing system using digital imaging. J. Hydraul. Eng., 130, 771-782.

Lin Y.T., Schuettpelz C.C., Wu C.H. and Fratta D., 2009. A combined acoustic and electromagnetic wave-based techniques for bathymetry and subbottom profiling in shallow waters. J. Appl. Geophys., 68, 203-218.

Lin Y.T., Wu C.H., Fratta D. and Kung K.-J.S., 2010. Integrated acoustic and electromagnetic wave-based technique to estimate subbottom sediment properties. Near Surf. Geophys., 8, 213-221. 
Losee R.F. and Wetzel R.G., 1993. Littoral flow rates within and around submersed macrophyte communities. Freshwater Biol., 29, 7-17.

Lougheed V.L., Crosbie B. and Chow-Fraser P., 1988. Predictions on the effect of common carp (Cyprinus carpio) exclusion on water quality, zooplankton, and submergent macrophytes in a Great Lakes wetland. Can. J. Fish. Aquat. Sci., 55, 1189-1197.

Maceina M.J. and Shireman J.V., 1980. The use of a recording fathometer for determination of distribution and biomass of hydrilla. J. Aquat. Plant Manage., 18, 34-39.

Madsen J.D. and Warnke E., 1983. Velocities of currents around and within submerged aquatic vegetation. Arch. Hydrobiol., 97, 389-394.

Madsen J.D., Chambers P.A., James W.F., Koch E.W. and Westlake D.F., 2001. The interaction between water movement, sediment dynamics and submersed macrophytes. Hydrobiologia, 444, 71-84.

Matsuzaki S.S., Usio N., Takamura N. and Washitani I., 2007. Effects of common carp on nutrient dynamics and littoral community composition: roles of excretion and bioturbation. Fund. Appl. Limnol., 168, 27-38.

McNeil J., Taylor C. and Lick W., 1996. Measurements of erosion of undisturbed bottom sediments with depth. $J$. Hydraul. Eng., 122, 316-324.

Mehta A.J. and Parchure T.M., 2000. Surface erosion of fine-grained sediment revisited. In: Flemming B.W., Delafontaine M.T. and Liebezeit G. (eds.), Muddy coast dynamics and resource management, Elsevier, Amsterdam, 55-74.

Miller S.A. and Crowl T.A., 2006. Effects of common carp (Cyprinus carpio) on macrophytes and invertebrate communities in a shallow lake. Freshwater Biol., 51, 85-94.

Morang A., Larson R. and Gorman L., 1997. Monitoring the coastal environment; Part III: geophysical and research methods. J. Coastal Res., 13, 1064-1085.

Nepf H.M., 1999. Drag, turbulence, and diffusion in flow through emergent vegetation. Water Resour. Res., 35, 479-489.

Nepf H., Ghisalberti M., White B. and Murph E., 2007. Retention time and dispersion associated with submerged aquatic canopies. Water Resour. Res, 43, W04422.

Nitsche F.O., Bell R., Carbotte S.M., Ryan W.B.E. and Flood R., 2004. Process-related classification of acoustic data from the Hudson River Estuary. Mar. Geol., 209, 131-145.

Petticrew E.L. and Kalff J., 1992. Water flow and clay retention in submerged macrophyte beds. Can. J. Fish. Aquat. Sci., 49, 2483-2489.

Roberts J., Chick A., Oswald L. and Thomoson P., 1995. Effect of carp, Cyprinus carpio L., an exotic benthivorous fish, on aquatic plants and water quality in experimental ponds. Mar. Freshwater Res., 46, 1171-1180.

Sabol B.M., Melton R.E. and Chamberlain R. Jr., Doeing P. and Haunert K., 2002. Evaluation of a digital echo sounder system for detection of submersed aquatic vegetation. Estuaries, 25, 133-141.

Sambuelli L. and Bava S., 2012. Case study: a GPR survey on a morainic lake in northern Italy for bathymetry, water volume and sediment characterization. J. Appl. Geophys., 81, 48-56.

Sand-Jensen K., 1998. Influence of submerged macrophytes on sediment composition and near-bed flow in lowland streams. Freshwater Biol., 39, 663-679.

Santamarina J.C., Rinaldi V.A., Fratta D., Klein K.A., Wang Y.H., Cho G.C., Cascante G., 2005. A survey of elastic and electromagnetic properties of near-surface soil. In: Butler K. (ed.), Near Surface Geophysics, Society of Exploration Geophysicists, Tulsa, 71-87.

Scheffer M., Hosper S.H., Meijer M.L., Moss B. and Jeppesen E., 1993. Alternative equilibria in shallow lakes. Trends Ecol. Evol., 8, 275-279.

Scheffer M., Rinaldi S., Gragnani A., Mur L.R. and VanNes E.H., 1997. On the dominance of filamentous cyanobacteria in shallow, turbid lakes. Ecology, 78, 272-282.

Schrage L.J. and Downing J.A., 2004. Pathways of increased water clarity after fish removal from Ventura Marsh: a shallow, eutrophic wetland. Hydrobiologia, 511, 215-231.

Sellmann P.V., Delaney A.J., Arcone S.A., 1992. Sub-bottom surveying in lakes with ground-penetrating radar. CRREL Report 92-8, U.S. Army Engineering Cold Regions Research and Engineering Laboratory, Hanover, NH.

Shawab W.C., Rodrigues R.W., Danforth W.W. and Gowen M.H., 1996. Sediment distribution on a stormdominated insular shelf, Luquillo, Puerto Rico, U.S.A. J. Coastal Res., 12, 147-159.

Trebitz A.S., Nichols S.A., Carpenter S.R. and Lathrop R.C., 1993. Patterns of vegetation change in Lake Wingra following a Myriophyllum spicatum declie. Aquat. Bot., 46, 325-340.

Wenta R., Sorsa K., Hyland G. and Schneider T., 2009. City of Madison Road Salt Report 2008-2009. Public Health Madison - Dane County. Available online at: http://www. cityofmadison.com/engineering/stormwater/documents/ RoadSalt2009.pdf.

Wilkens R.H. and Richardson M.D., 1998. The influence of gas bubbles on sediment acoustic properties: in situ, laboratory, and theoretical results from Eckernforde Bay, Baltic Sea. Cont. Shelf Res., 18, 1859-1892.

Zambrano L., Scheffer M. and Martinez-Ramos M., 2001. Catastrophic response of lakes to benthivorous fish introduction. Oikos, 94, 344-350. 